\title{
Winding Arrangement of High-frequency Amorphous Transformers for MW-class DC-DC Converters
}

\author{
H. Tanaka, K. Nakamura, and O. Ichinokura \\ Graduate School of Engineering, Tohoku University, 6-6-05 Aoba, Aramaki, Aoba-ku, Sendai 980-8579, Japan
}

\begin{abstract}
Many offshore wind-power generators over MW-class are currently in operation in Europe and are now starting to be used in Japan. In order to develop large-scale offshore wind-power plants, we need to reduce the size and weight of power converters, including isolating transformers. A dc-dc converter with a high-frequency transformer is one of the best ways to reduce the size and weight. However, copper loss of the transformer due to proximity effect is a problem because the operating frequency is increased from the commercial frequency to several $\mathrm{kHz}$. In this work, we investigate an interleaved winding arrangement for the high-frequency transformer. We compared the winding resistances of the interleaved and non-interleaved winding arrangements in an experiment using a test amorphous transformer and found that the interleaved winding arrangement inhibits the proximity effect and reduces the winding resistance. We designed an MW-class high-frequency amorphous transformer with the interleaved winding and demonstrated its very high efficiency.
\end{abstract}

Key words: dc-dc converter, amorphous transformer, interleaved winding, proximity effect

\section{Introduction}

Offshore wind-power generation is expected to substitute for conventional thermal power and nuclear power generations. In Europe, a large number of over MW-class offshore wind-power generators are already operated ${ }^{1)}$, and it has started in Japan. Such a large-scale offshore wind-power plant requires a MW-class dc-dc converter to efficiently send the generated power by high voltage direct current (HVDC) transmission system ${ }^{2}$.

Fig. 1 shows a basic configuration of the wind-power generation system by HVDC. In the system, a permanent magnet synchronous generator (PMSG) is employed because of high power, high efficiency, and maintenance free operation. The $\mathrm{dc}-\mathrm{dc}$ converter requires a MW-class transformer for isolating and boosting.

To reduce size and weight of such a large-capacity transformer, an amorphous core is employed and its operating frequency is increased from commercial frequency to several-kHz. However, it is expected that copper loss of the transformer becomes large due to proximity effect ${ }^{3)}$.

To overcome the above problem, this paper investigates an interleaved winding arrangement. First, leakage flux distribution and current density distribution of the interleaved and non-interleaved windings are compared by using finite element method (FEM). Next, frequency

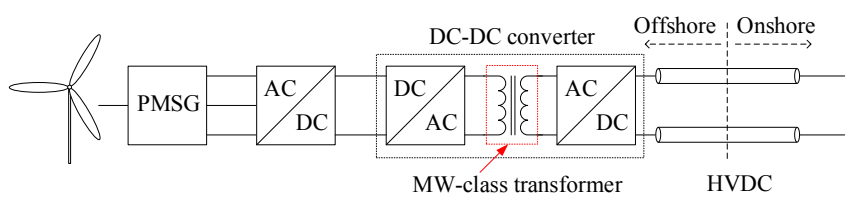

Fig. 1 Basic configuration of wind-power generation system by HVDC. dependences of the winding resistance of the interleaved and non-interleaved windings are compared experimentally by using a test amorphous transformer. Finally, a MW-class amorphous transformer with the interleaved winding is designed and calculated the loss and efficiency.

\section{Comparison of the winding arrangements based on measurement and calculation}

\subsection{Calculated results}

Fig. 2(a) illustrates shape and winding arrangement of a test amorphous transformer with the non-interleaved winding, and (b) shows with the interleaved winding. The height, width, and thickness of the transformer are 235 $\mathrm{mm}, 135 \mathrm{~mm}$, and $95 \mathrm{~mm}$, respectively. As shown in the figures, the winding shape is rectangular, and its size is 7 $\mathrm{mm}$ width by $0.8 \mathrm{~mm}$ thickness. The numbers of the primary and secondary windings are 96 each.

In the FEM calculation, the primary winding is excited by ideal sinusoidal current, and the secondary winding is shorted in the same way as a short-circuit test of the transformer. The electric resistivity of the primary and secondary wires is $2.52 \times 10^{-8} \Omega \cdot \mathrm{m}$ and the relative permeability of the magnetic core is 5000 .

Figs. 3 and 4 indicate leakage flux density distribution around the non-interleaved and interleaved windings at an operating frequency of $3 \mathrm{kHz}$. The figures reveal that the interleaved winding arrangement can significantly reduce the leakage flux around the windings.

Figs. 5 and 6 show current density distribution of the non-interleaved and interleaved windings and their enlarged views. It is understood that the current distribution of the non-interleaved winding is non-uniform due to the proximity effect. On the other hand, the current density distribution of the interleaved 
winding is uniform.

Fig. 7 indicates calculated frequency dependence of the winding resistances of the transformers with the interleaved and non-interleaved windings. It is clear that the winding resistance of the non-interleaved winding is considerably increased even though an operating frequency is below $1 \mathrm{kHz}$. On the other hand, the winding resistance of the interleaved winding is almost constant.

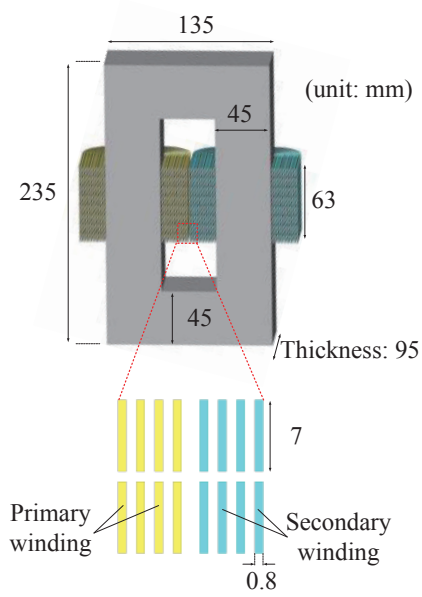

(a) Non-interleaved winding arrangement

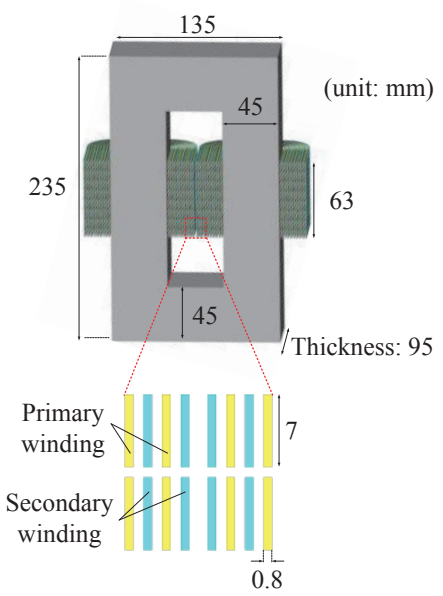

(b) Interleaved winding arrangement

Fig. 2 Shape and winding arrangement of a test amorphous transformer.
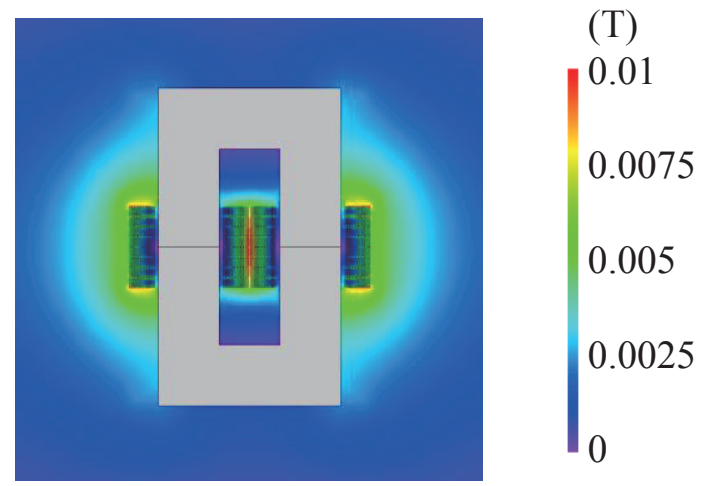

Fig. 3 Leakage flux density distribution around the non-interleaved winding $(f=3 \mathrm{kHz})$.

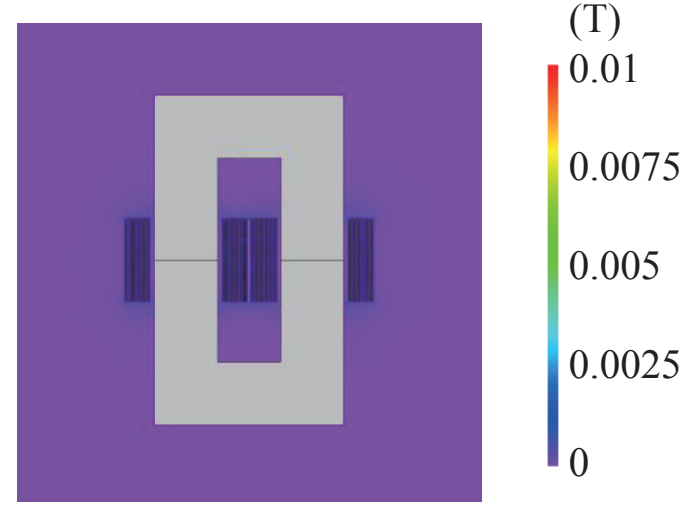

Fig. 4 Leakage flux density distribution around the interleaved winding $(f=3 \mathrm{kHz})$.

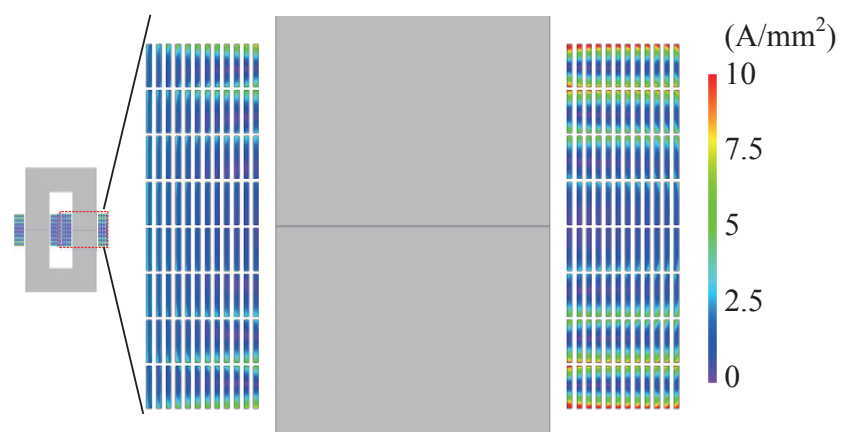

Fig. 5 Current density distribution of the non-interleaved winding and its enlarged view $(f=3 \mathrm{kHz})$.

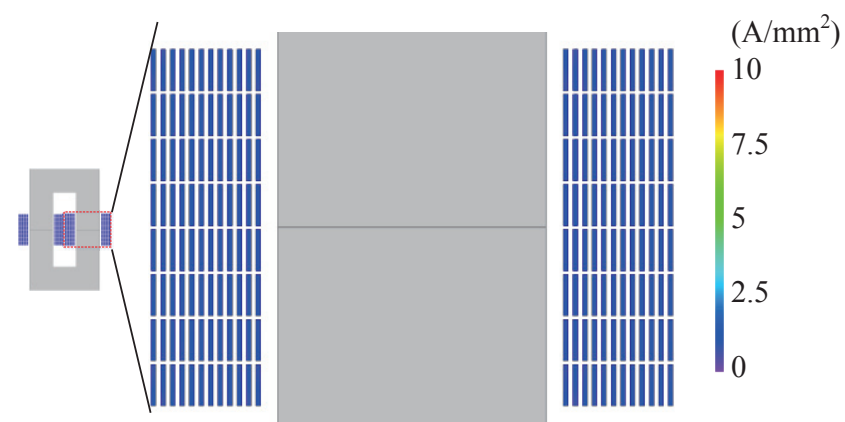

Fig. 6 Current density distribution of the interleaved winding and its enlarged view $(f=3 \mathrm{kHz})$.

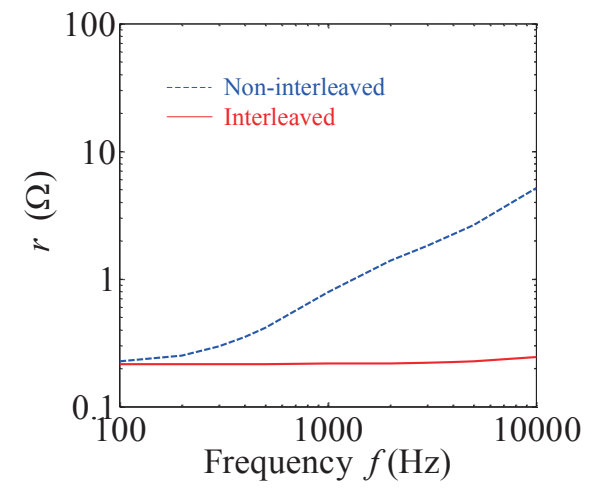

Fig. 7 Frequency dependence of the winding resistances calculated by FEM. 


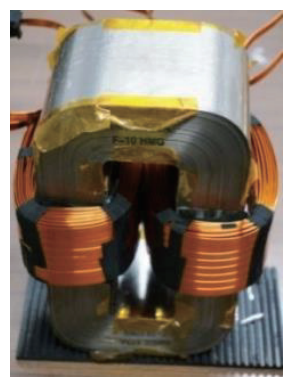

Fig. 8 The test amorphous transformer.

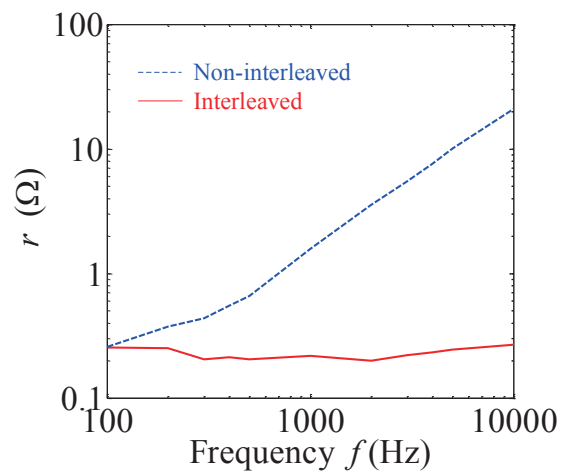

Fig. 9 Measured frequency dependence of the winding resistances.

\subsection{Measured results}

Fig. 8 shows an appearance of the test amorphous transformer. The shape and the winding arrangements are the same as the transformers shown in Fig. 2.

Fig. 9 indicates measured frequency dependence of the winding resistances of the transformers with the interleaved and non-interleaved windings. The figure reveals that the winding resistance of the non-interleaved winding is increased remarkably in the same manner as the calculation result shown in Fig. 7. It is proved experimentally that the interleaved winding arrangement can significantly reduce the winding resistance. The causes of error between the calculated and measured values of non-interleaved winding arrangement could be that the calculated values are obtained from the 2D-FEM.

\section{Design of high-frequency amorphous transformer for MW-class dc-dc converters}

\subsection{Specifications of MW-class amorphous transformer}

Based on the above results, a MW-class amorphous transformer with the interleaved winding is designed and compared to the transformer with the non-interleaved winding. In the design of the amorphous transformer, insulation distance of the adjacent windings is different according to the winding arrangement. The insulation distance of the non-interleaved winding arrangement is 1 $\mathrm{mm}$, while the insulation distance of the interleaved winding arrangement is increased to $5 \mathrm{~mm}$ because the primary and secondary windings are adjacent to each other.

Table 1 shows specifications of the amorphous transformer for MW-class dc-dc converters. A turn ratio of the transformer is 10 .

Fig. 10 illustrates shape and winding arrangement of the amorphous transformers for MW-class dc-dc converters, which satisfy the required specifications shown in Table 1. The height, width, and thickness of the transformer with the non-interleaved winding are 321 $\mathrm{mm}, 234 \mathrm{~mm}$, and $202 \mathrm{~mm}$, respectively. On the other hand, the height, width, and thickness of the transformer with the interleaved winding are $321 \mathrm{~mm}, 338 \mathrm{~mm}$, and $202 \mathrm{~mm}$, respectively. As shown in the figure, the winding shape is rectangular. The size of the primary winding is $100 \mathrm{~mm}$ width by $2.0 \mathrm{~mm}$ thickness, while the size of the secondary winding is $10 \mathrm{~mm}$ width by $2.0 \mathrm{~mm}$ thickness. The numbers of the primary and secondary windings are 14 and 140 , respectively.

Table 1 Specifications of the amorphous transformer for MW-class dc-dc converters.

\begin{tabular}{|l|r|}
\hline Frequency $f$ & $3 \mathrm{kHz}$ \\
\hline Rated power $P$ & $1.0 \mathrm{MW}$ \\
\hline Input voltage $V_{1}$ & $1.65 \mathrm{kV}$ \\
\hline Output voltage $V_{2}$ & $16.5 \mathrm{kV}$ \\
\hline Max. flux density $B_{m}$ & $1.0 \mathrm{~T}$ \\
\hline Current density $J$ & $3 \mathrm{~A} / \mathrm{mm}^{2}$ \\
\hline
\end{tabular}

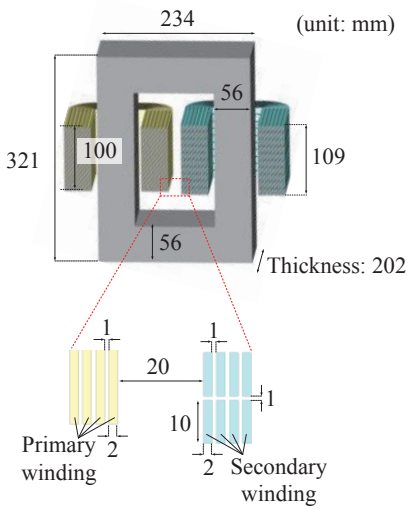

(a) Non-interleaved winding arrangement

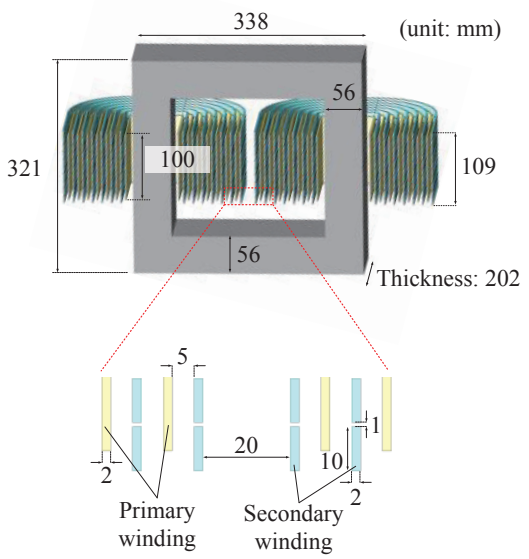

(b) Interleaved winding arrangement

Fig. 10 Shape and winding arrangement of the amorphous transformers for MW-class dc-dc converters. 


\subsection{Calculated results}

Fig. 11 indicates calculated frequency dependence of copper losses of the MW-class transformers. In the FEM calculation, the primary winding is excited by the ideal sinusoidal current, and the secondary winding is shorted. The figure reveals that the copper loss of the non-interleaved winding is increased considerably, and that the interleaved winding arrangement can remarkably reduce the copper loss.

Table 2 shows calculated losses of the MW-class transformers. The core loss of the transformer is calculated based on the Bertotti's equation ${ }^{4)}$ :

$$
W_{i}=A_{h} f B_{m}^{2}+A_{e} f^{2} B_{m}^{2}+A_{a} f^{1.5} B_{m}^{1.5},
$$

where the frequency is $f$, and the maximum flux density is $B_{m}$. In (1), the first term shows dc hysteresis loss, the second term indicates classical eddy current loss, and the third term expresses anomalous eddy current loss, respectively. The parameters $A_{h}, A_{e}$, and $A_{a}$ can be found by approximating $W_{i} / f-f$ curves of core material based on least-square method as shown in Fig. 12. The parameters $A_{h}, A_{e}$, and $A_{a}$ are obtained as $A_{h}=4.31 \times 10^{-3}, A_{e}=1.81 \times$ $10^{-7}$, and $A_{a}=6.38 \times 10^{-5}$, respectively.

It is understood from Table 2 that the interleaved winding arrangement is very useful for the high-frequency transformer of the MW-class dc-dc converters from the view point of the copper loss and the thermal design.

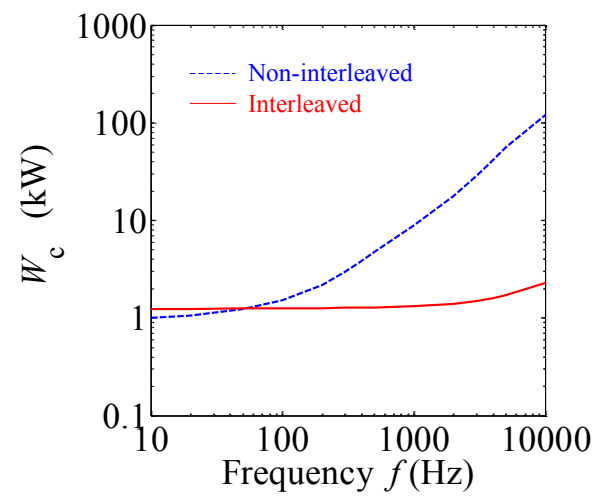

Fig. 11 Calculated frequency dependence of copper losses of the MW-class amorphous transformers.

Table 2 Calculated losses of the MW- class amorphous transformers $(f=3 \mathrm{kHz})$.

\begin{tabular}{|c|c|c|}
\hline & $\begin{array}{c}\text { Non-interleaved } \\
\text { winding arrangement }\end{array}$ & $\begin{array}{c}\text { Interleaved winding } \\
\text { arrangement }\end{array}$ \\
\hline $\begin{array}{c}\text { Core loss } \\
W_{i} \quad(\mathrm{~kW})\end{array}$ & 1.5 & 1.8 \\
\hline $\begin{array}{c}\text { Copper loss } \\
W_{c}(\mathrm{~kW})\end{array}$ & 28.6 & 1.5 \\
\hline $\begin{array}{c}\text { Total loss } \\
W_{i}+W_{c}(\mathrm{~kW})\end{array}$ & 30.1 & 3.3 \\
\hline $\begin{array}{c}\text { Transformer } \\
\text { efficiency }(\%)\end{array}$ & 97.0 & 99.7 \\
\hline
\end{tabular}

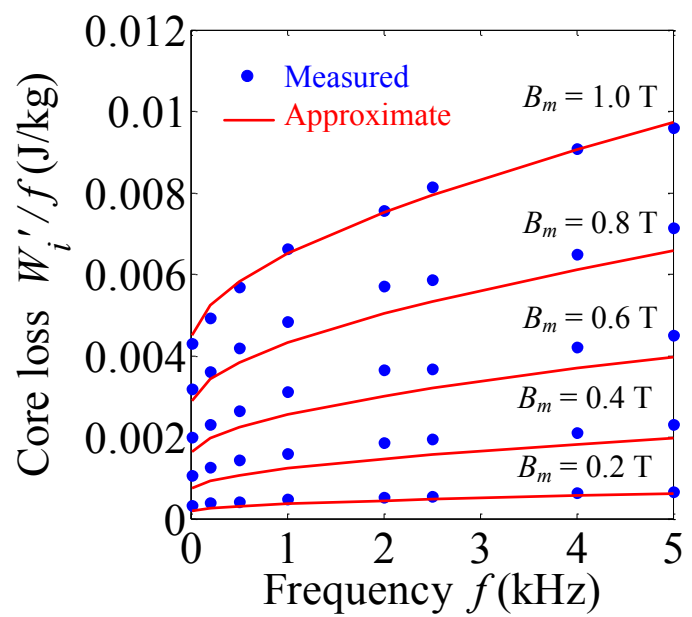

Fig. $12 W_{i} / f$ - $f$ curves and their approximate curves of amorphous core.

\section{Conclusion}

This paper investigated the winding arrangement of the high-frequency amorphous transformer for MW-class dc-dc converters. By comparing the frequency dependences of the winding resistance of the interleaved and non-interleaved winding arrangements, it was clear that the interleaved winding arrangement can significantly reduce the winding resistance.

In addition, the 1.0 MW amorphous transformer with the interleaved winding was designed. It was found that the interleaved winding arrangement is very useful for the MW-class high-frequency amorphous transformer from the view point of the copper loss reduction.

This work was supported by Grant-in-Aid for JSPS Fellows (26-5193).

\section{References}

1) J. Twidell and G. Gaudiosi: Offshore Wind Power, (Multi-Science Publishing, Brentwood, 2009).

2) G. Ortiz, J. Biela, D. Bortis, J.W. Kolar, 2010 International Power Electronics Conference (IPEC 2010), 3212 (2010).

3) P.L. Dowell, The Proceedings of the Institution of Electrical Engineers, 113, 1387 (1966).

4) G. Bertotti, IEEE Trans. Magn., 24, 621 (1988).

Received Oct 19, 2015; Accepted Dec 29, 2015 